\title{
EL LEGADO MONTPENSIER AL AYUNTAMIENTO DE SEVILLA
}

\author{
por Teodoro Falcon Márquez
}

\begin{abstract}
En 1898 los herederos de la infanta María Luisa Fernanda, duquesa de Montpensier, donaron al Ayuntamiento de Sevilla 51 lienzos, que decoraban la escalera principal del Palacio de San Telmo. Se trata de una galería de personajes ilustres, de las artes, las letras y milicia, así como de reyes. Fundamentalmente son obras de Antonio Cabral Bejarano y sus hijos y, de Joaquín Domínguez Bécquer, entre las que figuran copias de Murillo y Zurbarán, entre otros.
\end{abstract}

In 1898 the heirs of the Infanta María Luisa Fernanda, Duchess of Montpensier, donated to the Town Council of Seville 51 canvasses, which adomed the main staircase of the Palace of San Telmo. They form a collection of illustrious individuals from the world of the arts, letters and the military profession, as well as of royalty. They are basically the work of Antonio Cabral Bejarano and his sons, and of Joaquín Domínguez Bécquer, and include copies of works by Murillo, Zurbarán and others.

\section{Antecedentes}

Durante la segunda mitad del siglo XIX el Palacio de San Telmo de Sevilla, antigua sede del Colegio Seminario para Enseñanza Náutica, vivió su momento de máximo esplendor, a partir del establecimiento en este edificio de los duques de Montpensier, desde 1849 hasta la cesión del inmueble a la mitra en $1896^{1}$.

Como coleccionistas, Antonio de Orleans y María Luisa Fernanda de Borbón hicieron de San Telmo un verdadero museo, fundamentalmente de pinturas, que tuvo su origen en el legado familiar de la Casa de Orleans, la cual aportó una serie de cuadros de pintura española y francesa, así como retratos de Winterhalter. Menor fue la aportación de la infanta María Luisa, con cuadros de Goya, Esquivel, Vicente López y Madrazo, así como unos frescos procedentes del Palacio de Vista Alegre.

Estos fondos se fueron incrementando con nuevas adquisiciones, sobre todo de pintura española, entre las que figuraban algunos zurbaranes, procedentes de la Cartuja de Jerez y el retrato del Greco, que representa a su hijo Jorge Manuel, donado con posterioridad a la Academia de Bellas Artes de Sevilla y expuesta en su Museo de Pinturas.

1. FAlCon mÁrQUeZ, T.: El Palacio de San Telmo. Ediciones Gever. Sevilla, 1991. 
A causa de la imposibilidad de los duques de hacerse con muchos originales de la pintura española del siglo XVII, encargaron gran número de réplicas de obras de Murillo, Herrera el Viejo, Alonso Cano, Valdés Leal y Zurbarán, entre otros. Acorde con la "murillolatría" de la época, predominaban las copias de este pintor sevillano, realizadas por Antonio Cabral Bejarano y su hijo Francisco, y de José María Romero, Gutiérrez de la Vega, Manuel Quesada, e incluso por la reina María Cristina. De la preferencia por Murillo es también índice que en el Dormitorio de los Duques se hallaban las nueve copias siguientes: "Moisés haciendo brotar las aguas de la roca", "El Milagro de los panes y los peces", "La Adoración de los pastores", "Las santas Justa y Rufina", "Santo Tomás de Villanueva", "La Aparición del Niño Jesús a San Antonio", "San Juan Bautista" y el "Niño Jesús".

Más importante fue la labor de mecenazgo que llevaron a cabo los Duques becando artistas o encargándoles obras. Fruto de ello fue el gran número de cuadros de pintura sevillana contemporánea que engrosó la pinacoteca. Hasta tal punto fue así, que la Exposición. Provincial de Bellas Artes de 1858, se montó con obras exclusivamente de su propiedad. Entre las firmas hay que citar a Joaquín Domínguez Bécquer, que fue profesor de Dibujo de sus hijos; Cabral Bejarano y sus hijos, quienes decoraron el palacio; Antonio María Esquivel, José Escacena, Rafael Benjumea y Eduardo Cano, entre otros. También se incorporaron obras de Federico Madrazo y de Delacroix ${ }^{2}$.

Del patrimonio artístico que albergaba el palacio se publicó en 1866 un Catálogo ${ }^{3}$ en el que figuran cerca de mil obras, la mayor parte pinturas. Al año siguiente se editó un Apéndice, que más que una lista suplementaria de nuevas adquisiciones, en él se indican las variaciones de lugar que experimentaron algunas obras dentro del palacio. La realización del Catálogo se ha atribuido a Antonio Cabral Bejarano, pero hay que tener en cuenta que falleció en 1861; debió por tanto ser ultimado por sus hijos.

\section{El legado al Ayuntamiento}

El 2 de Febrero de 1897 falleció en el palacio de San Telmo la infanta María Luisa. En su testamento, fechado en 1893, donaba el edificio al arzobispo de Sevilla, para destinarlo a Seminario Eclesiástico. Por otro lado la mayor

2. DE LA BANDA Y VARGAS, A.: La colección pictórica de la infanta Luisa de Orleans. "Anales de la Universidad Hispalense”. Vol. XVIII. Años 1957-58. págs. 23-76. Idem. La Corte sevillana de los Montpensier. En "Homenaje al Dr. Muro Orejón". Universidad de Sevilla. Vol. I. Sevilla, 1979. págs. 283-296. VARIOS. Catálogo de la Exposición "La pintura en la época de los duques de Montpensier". Caja de Ahorros San Fernando. Sevilla, s/a.

3. CATÁLOGO de los cuadros y esculturas pertenecientes a la galería de SS.AA.RR. los Serenísimos Señores Infantes de Españd, duques de Montpensier. Sevilla, 1866. Editado por Francisco Alvarez y Cía., impresores de SS.AA.RR. y Honorario de S.M. 
parte de sus jardines lo cedía al Ayuntamiento, con destino a la creación del futuro Parque de María Luisa ${ }^{4}$. El ajuar fue repartido entre los dos hijos que le habían sobrevivido, el infante don Antonio y la infanta doña Isabel, condesa de París. Gran parte de esas piezas se llevó el palacio de Villamanrique y un importante lote fue donado por estos herederos al Ayuntamiento de Sevilla ${ }^{5}$.

Según oficio remitido por los albaceas testamentarios de la infanta María Luisa al Ayuntamiento, fechado en 21 de Octubre de 1898, los duques:

“...a quienes tenemos el alto honor de representar en la testamentaría de su Augusta e inolvidable Madre la Serenísima Sra. Infanta Doña Luisa Fernanda (Q.D.D.G.) se ha servido darnos el honroso encargo de ofrecer a ese Excmo. Ayuntamiento de su digna Presidencia, como donativo y en prueba del sincero y cariñoso afecto que siempre siente por este noble pueblo sevillano, donde han nacido, la colección de cuadros que adornan en la actualidad la escalera principal del Palacio de San Telmo, la cual se compone, como se detalla en la relación que es adjunta de cincuenta y un liénzos pintados al óleo en su mayoría retratos de ilustres y preclaros hijos de Sevilla y de gloriosa memoria".

La relación coincide con el Catálogo de los Cabral Bejärano. Su temática es una galería de personajes ilustres, que tiene su paralelismo con el grupo escultórico que hizo Susillo para la fachada Norte y con los relieves que decoran las enjutas de los arcos del patio principal. En la galería de retratos pictóricos los hay de reyes y personajes cortesanos: Alfonso X, Fernando III, Pedro I, D. a María Coronel, Isabel la Católica, Fernando el Católico y Carlos II.

Más numerosa es la serie de personajes ilustres de las letras, las artes y la milicia: Argote de Molina, Cristóbal Colón, Hernando Colón, Francisco de Rioja, Juan de la Cueva, Ortíz de Zúñiga, Mateo Alemán, Francisco Pizarro, Lope de Rueda, Calderón de la Barca, Martínez Montañés, Hernán Cortés, Murillo, Almirante Ulloa, Arias Montano, Nicolás Antonio, Rodrigo Ponce de León (Marqués de Cádiz), Velázquez, Roelas, Cervantes, Pacheco, Lope de Vega, Nicolás Monardes, Félix José Reinoso, Ambrosio Spínola, Mal-Lara, Alberto Lista, Fernando Herrera, Francisco Herrera el Viejo y Zurbarán.

Finalmente otro gran apartado lo constituyen retratos de santos y religiosos: San Leandro, San Isidoro, santas Justa y Rufina, San Hermanegildo, Santa Teresa de Jesús, Venerable Contreras, Fray Diego de Cádiz, Hermano Toribio, Madre Dorotea, Miguel de Mañara y Fray Juan Félix Girón.

4. Archivo General del Arzobispado de Sevilla, Legajo 730, n. ${ }^{\circ}$ 5. Archivo Municipal de Sevilla. Sección O.P. "Varios". Carpeta 445.

5. A.M.S. Sección Asuntos Especiales. Año 1898, n. $^{\circ} 14$. 
De la ubicación de estos cuadros en la escalera principal de San Telmo existe un importante documento gráfico, una fotografía de Lucien Lèvy efectuada hacia $1883^{6}$. En ella se puede apreciar que en la parte superior de la escalera había unos tondos de vírgenes sobre balcones interiores de la caja de la escalera, distinguiéndose la Virgen de Regla. En ese mismo testero Norte, a los lados del balcón estaban las copias de Murillo de San Isidoro y San Leandro. Debajo, el Venerable Contreras, y en el rellano, la galería de retratos de personajes ilustres pertenecientes al mundo de las artes, las letras y la milicia. En la última meseta, dando acceso a la planta alta, había un dosel.

Los autores de los cuadros son diversos artistas, siendo la mayoría copias. De Antonio Cabral Bejarano son los tondos que representan a las vírgenes de Regla, del Rocío, del Amparo, de los Reyes, la Antigua, la Salud y la Hiniesta. De su hijo Francisco Cabral destaca las santas Justa y Rufina, copias de Murillo. Más importantes son los retratos que realizó Joaquín Domínguez Bécquer de Fernando III, Alfonso X, doña María Coronel, Isabel la Católica, Fernando el Católico y Alberto Lista; este último copia del original suyo de la Academia de Buenas Letras. De Alfred Dehodencq el retrato de Santa Teresa de Jesús, copia de Juan de la Miseria, que se conserva en el convento de Carmelitas Descalzas (Las Teresas). El resto son copias de Zurbarán, Valdés Leal, Herrera el Viejo, Pacheco, Alonso Cano y de una serie de retratos existentes en diversas galerías nacionales y extranjeras.

De los cincuenta y un cuadros destacaremos especialmente a tres: los retratos de Carlos II, Pedro I y Fernando III. El de Carlos II es un lienzo de 2,08 x 1,44 m. En el Catálogo de 1866 consta: "Escuela madrileña, n. ${ }^{\circ} 22$. Retrato de cuerpo entero de Carlos II, Rey de España. Alto 7 pies, 6 pulgadas; ancho 5 pies, 2 pulgadas. Procedente de la Sala de Juntas del extinguido Colegio de San Telmo". Ello parece evidenciar que no fue adquirido por los Duques de Montpensier para su colección, ya que se encontraría desde su origen en el Colegio Seminario, por ser el rey que firmó la Real Cédula de su fundación en 1681. En la actualidad se halla en el Despacho de la Alcaldía. El lienzo debió realizarse hacia $1677-79$, cuando el rey tendría 17 ó 18 años. Es obra de taller de Juan Carreño de Miranda, semejante al que se conserva en la colección del conde de Harrach, en Viena ${ }^{7}$.

Muy interesante es también el retrato de Pedro I de Castilla. Es un lienzo de 1,14 x 0,92 m., firmado por Joaquín D. Bécquer en 1857. En la parte superior derecha se reproduce la firma del rey. En el Catálogo de 1866 figura con el número 107, ubicado en la escalera principal y con las medidas: "Alto

6. VARIOS. Andalucía Americana. Edificios vinculados con el Descubrimiento y la Carrera de Indias. Sevilla, 1989 , pág. 238.

7. AYUNTAmiento de Sevilla. Colección de Pinturas. Sevilla, 1983. n. ${ }^{\circ} 17$ del Catálogo. 
4 pies, ancho 3 pies 4 pulgadas". Es un espléndido retrato, de tres cuartos, con el rey vistiendo ropón rojo de brocado de oro y manto verde de igual tejido. En la actualidad está depositado en la Secretaría particular del Alcalde.

Finalmente destacaremos el de Fernando III. Mide 1,15 x 0,92 m. Es un retrato de tres cuartos, con el rey vestido según la iconografía tradicional del siglo XVII. Estaba ubicado en la escalera principal de San Telmo, con el número 105. Las medidas que se dan en el Catálogo de los Cabral son: "Alto 3 pies 6 pulgadas, ancho 3 pies". Figura como atribuido a Francisco de Zurbarán. Collantes de Terán lo cataloga como obra anónima de escuela sevillana de mediados del siglo XVII ${ }^{8}$. Estoy de acuerdo con los autores del Catálogo de la colección de pinturas del Ayuntamiento, al señalar que es una obra de comienzos del siglo XVIII, muy repintada, que deriva por fisonomía y tratamiento, de modelos zurbaranescos de hacia mediados del siglo anterior.

En la actualidad, debido a las obras de restauración que se realizan en la sede central del Ayuntamiento, el palacio renacentista, esta colección se halla depositada provisionalmente en el ex-convento de los Terceros.

8. COLLANTES DE TERÁN Y DELORME, F.: El Patrimonio Monumental y Artístico del Ayuntamiento de Sevilla. Sevilla, 1970. pág. 36. 


\section{APÉNDICE DOCUMENTAL}

1898, Octubre 21. Sevilla. Inventario de los cuadros donados al Ayuntamiento por los herederos de la infanta María Luisa.

(A.M.S. Sección Asuntos Especiales. año 1898, n. ${ }^{\circ}$ ).

Nota expresiva de cincuenta y un cuadros pintados al óleo, donados por S.A.R. el Srmo. Sr. Infante D. Antonio de Orleans y S.A.R. la Srma. Sra. Infanta, D. Isabel de Orleans, condesa de París, al Excmo. Ayuntamiento de Sevilla, procedentes de la Galería del Palacio de San Telmo.

Copia de Murillo $n .^{\circ} 104$ del Catálogo $=$ San Leandro, Arzobispo de Sevilla.

Id. Id. n. ${ }^{\circ} 103 \quad "=$ San Isidoro, Arzobispo de Sevilla.

Francisco Bejarano, $\mathrm{n} .{ }^{\circ} 101 \quad " \quad=$ Santa Justa, patrona de Sevilla.

Id. Id. $n .{ }^{\circ} 102 \quad " \quad=$ Santa Rufina, id. id.

Atribuido a Zurbarán, $n .^{\circ} 105 \quad "=$ San Fernando.

Copia de Herrera el Viejo " $\quad=$ San Hermenegildo.

Copiado por Alfredo Dehodencq de Fray Juan de la Miseria, $n .^{\circ} 115=$ Santa Teresa de Jesús.

Joaquín Bécquer $n .{ }^{\circ} 115=D{ }^{a}$ María Coronel.

Id. Id. $n .{ }^{\circ} 108=\mathrm{D}$. Alonso el Sabio.

Id. Id. n. $.^{\circ} 107=$ Retrato de D. Pedro $1 .^{\circ}$ de Castilla.

Id. Id. n. ${ }^{\circ} 139=$ Id. D. ${ }^{a}$ Isabel la Católica.

Id. Id. $n .^{\circ} 140=$ Id. de D. Fernando el Católico.

Escuela Sevillana $n .{ }^{\circ} 111=$ Id. de Gonzalo Argote de Molina.

Id. Id. n. ${ }^{\circ} 199=$ Id. de Fernando Colón.

Escuela Madrileña n. ${ }^{\circ} 520=$ Id. de Cristóbal Colón.

Escuela Sevillana $n .^{\circ} 109=$ Id. D. Francisco de Rioja.

Id. Id. n. ${ }^{\circ} 112=$ Id. de Juan de la Cueva.

Id. Id. n. ${ }^{\circ} 113=$ Id. del Venerable Contreras.

Id. Id. n. ${ }^{\circ} 117=$ Id. de Diego Ortíz de Zúniga.

Escuela Sevillana n. ${ }^{\circ} 119=$ Retrato de Mateo Alemán.

Escuela Española n. ${ }^{\circ} 142=$ Id. de Francisco Pizarro.

Escuela Sevillana n. ${ }^{\circ} 120=$ Id. de Lope de Rueda.

Copia de Alonso Cano n. ${ }^{\circ} 521$ = Id. de Pedro Calderón de la Barca.

Escuela Sevillana $n .^{\circ} 123=$ Id. de Juan Martínez Montañés.

Copia de Alonso Cano n. ${ }^{\circ} 125$ = Id. de Calderón de la Barca.

Escuela Española n. ${ }^{\circ} 126=$ Id. de Hernán Cortés.

Copia de Murillo n. ${ }^{\circ} 129=$ Id. de Bartolomé Esteban Murillo.

Escuela Sevillana n. ${ }^{\circ} 130=$ Id. del Almirante Antonio Ulloa.

Id. Id. n. ${ }^{\circ} 122=$ Id. de Benito Arias Montano.

Id. Id. n. ${ }^{\circ} 121=$ Id. de Nicolás Antonio.

Id. Id. n. ${ }^{\circ} 131=1 d$. de D. Rodrigo Ponce de León, Marqués de Cádiz.

Escuela Española n. ${ }^{\circ} 128=$ Id. de Diego Velázquez de Silva. 
Escuela Sevillana $n .^{\circ} 141=\mathrm{Id}$. de Juan de las Roleas.

Escuela Española n. ${ }^{\circ} 127=$ Id. de Miguel de Cervantes.

Escuela Sevillana n. $124=$ Id. de Francisco Pacheco.

Escuela Madrileña n. ${ }^{\circ} 522=$ Id. de Félix López de Vega.

Escuela Sevillana n. ${ }^{\circ} 523=$ Id. de Fray Diego de Cádiz.

Id. Id. n. $.^{\circ} 143=$ Id. del Hermano Toribio.

Id. Id. $\quad n .{ }^{\circ} 524=$ Id. de Nicolás Monardes.

Id. Id. $n .^{\circ} 133=$ Id. de Félix José Reinoso.

Copia de Murillo n. ${ }^{\circ} 144=$ Id. de la Madre Dorotea.

Id. de Valdés Leal n. ${ }^{\circ} 134=$ Id. de D. Miguel de Mañara.

Escuela Sevillana n. ${ }^{\circ} 138=$ Id. de Fray Juan Félix Girón.

Id. Id. $n .^{\circ} \mathbf{1 3 7}=$ Retrato de Ambrosio de Espínola.

Id. Id. $n . .^{\circ} 136=$ Id. de Juan de Mal-Lara.

Id. Id. n. ${ }^{\circ} \mathbf{1 3 5}=$ Id. de Diego Ortíz de Zúñiga.

Copia de Joaquín Bécquer $n .{ }^{\circ} 132=I d$. de D. Alberto Lista.

Escuela Sevillana n. $.^{\circ} 110=$ Id. de Fernando Herrera el Divino.

Id. Id. $\quad n .^{\circ} 118=$ Id. de Francisco Herrera el Viejo.

Francisco Zurbarán. Retrato del mismo.

Escuela Española. Retrato de cuerpo entero de Carlos 2. ${ }^{\circ}$ Rey de España.

Todos los referidos cuadros tienen marcos iguales de madera tallada y dorada con adornos azules.

Sevilla 21 de Octubre de 1898.

Los Albaceas de S.A.R. Serma. Sra. Infanta D ${ }^{a}$ Luisa Fernanda.

Firmado: Miguel Velarde. Luis Lerdo de Tejada. 


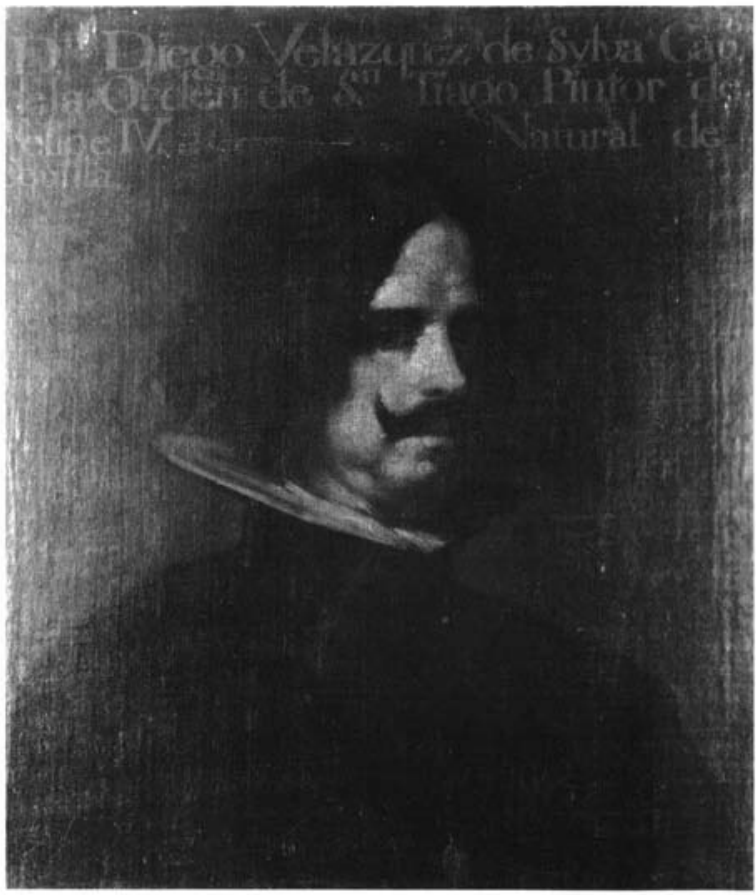

Diego de Velízquez. 


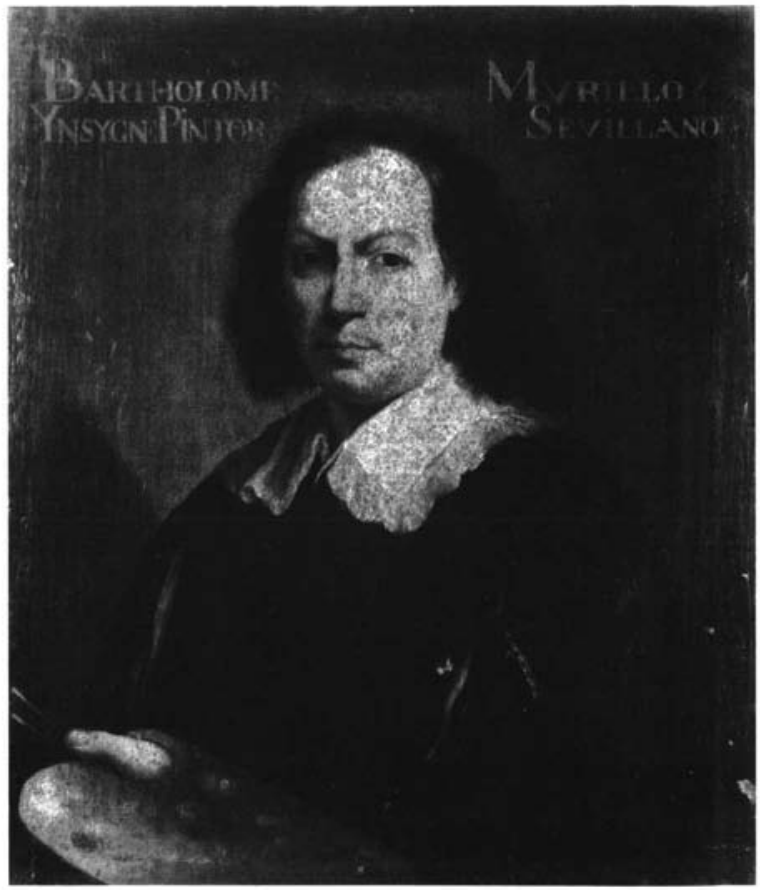

Bartolomé Esteban Murillo. 


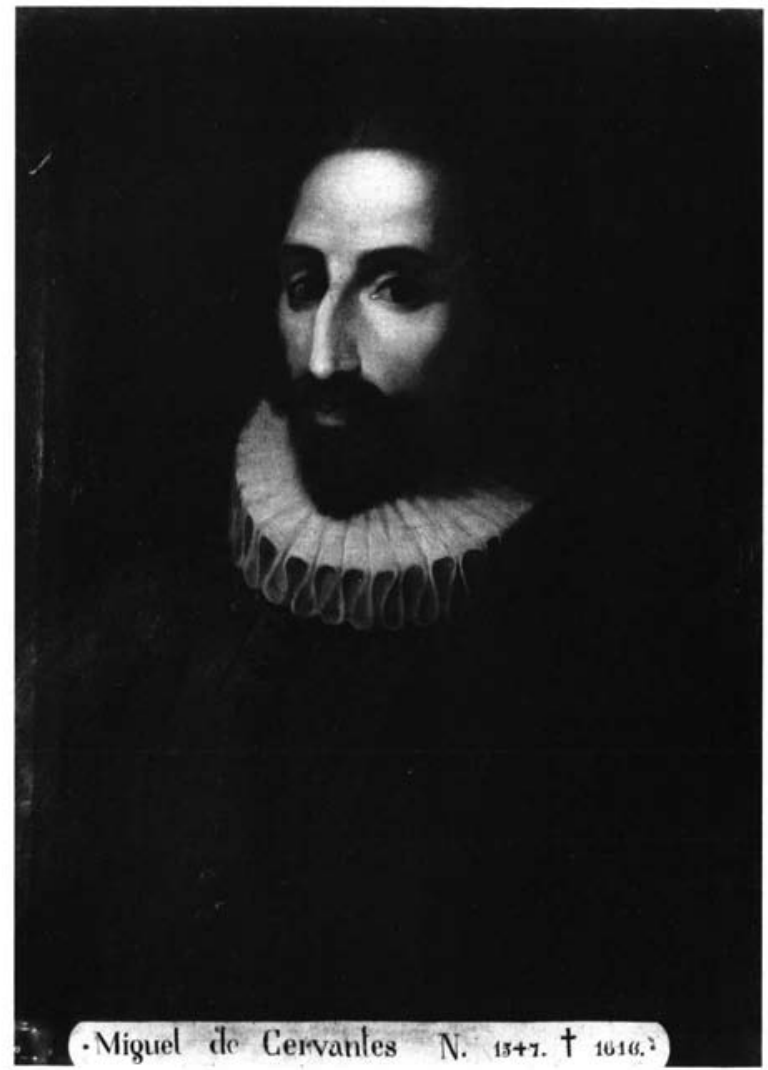

Miguel de Cervantes. 


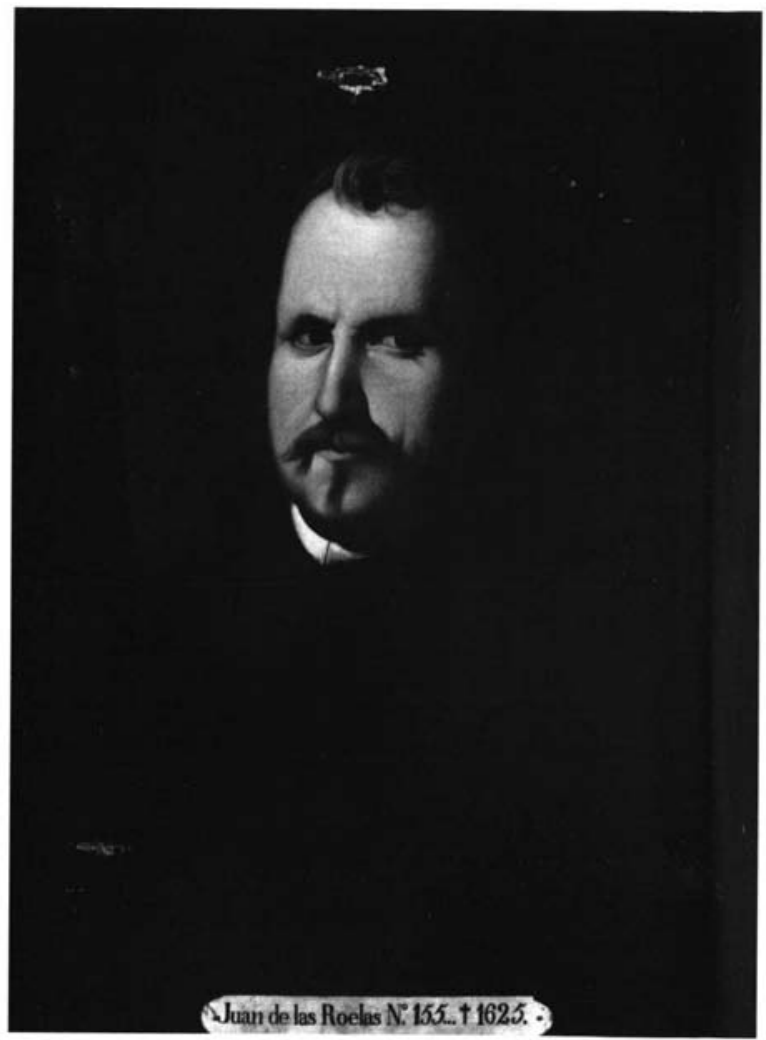

Juan de las Roelas. 